\title{
GÊNEROS TEXTUAIS: IMPRESCINDÍVEIS NO ENSINO-APRENDIZAGEM
}

\author{
Maria Gorette da Silva ${ }^{1}$ \\ André Neres de Lima²
}

RESUMO: Este trabalho defende o uso dos gêneros textuais para a aquisição e construção dos saberes linguísticos e não linguísticos na aprendizagem da Língua Portuguesa, na vida escolar do aluno. Eles servem de suporte e instrumento pedagógico na postura consciente do professor, para a formação de valores não meramente em atividade de sala de aula, mas também na tomada de decisões para a solução de conflitos, promovendo experiências para o enriquecimento das habilidades e competências dos educandos. Esta pesquisa possui caráter bibliográfico, e mostra o embasamento teórico através de consultas a diversos livros de autores renomados acerca do assunto em estudo. Fundamenta-se na utilização dos gêneros textuais, pois com eles, seus usuários constroem visões de mundo, estimula-se o gosto pela leitura e escrita. Os gêneros contribuem também para a reflexão sobre a Língua, interação das práticas sociais, ascensão do indivíduo às variadas formas de comunicação. Por meio destes usos de forma processual, e progressiva, o educando abrirá novos horizontes, construirá conhecimento, escrevendo, assim, sua cidadania.

Palavras-chave: Gêneros textuais. Língua Portuguesa. Ensino-Aprendizagem.

ABSTRACT: This work defends the use of textual genres for the acquisition and construction of linguistic and non-linguistic knowledge in Portuguese language learning, in the student's school life. They serve as a support and pedagogical tool in the teacher's conscious posture, for the formation of values not merely in classroom activities, but also in decision-making for conflict resolution, promoting experiences to enrich the skills and competences of students. This research has a bibliographic character, and shows the theoretical basis through consultations to several books by renowned authors on the subject under study. It is based on the use of textual genres, because with them, its users build views of the world, stimulating a taste for reading and writing. The genres also contribute to the reflection on Language, interaction of social practices, the rise of the individual to various forms of communication. Through these uses in a procedural and progressive way, the student will open new horizons, build knowledge, thus writing their citizenship.

Keywords: Textual genres. Portuguese language. Teaching-learning.

\footnotetext{
${ }^{1}$ Graduada em Letras, pela Faculdade de formação de Professores da Mata Sul (FAMASUL), Pós-Graduada em Metodologia em Língua Portuguesa e Língua Estrangeira, pela UNINTER, Pós-Graduanda em Ciências da Educação, pela Veni Creator Christian University.E-mail: mgorettesv@gmail.com.

${ }^{2}$ Graduado em Pedagogia pela Universidade de Pernambuco (UPE), Especializado em Educação de Jovens e Adultos, pelo Instituto Federal de Pernambuco (IFPE), Pós-Graduando em Ciências da Educação pela Veni Creator Christian University. E-mail: andreneresi985@gmail.com.
} 


\section{INTRODUÇÃO}

Em várias formas de abordagem da teoria dos gêneros textuais, vê-se uma unanimidade de atribuição às noções de comunidade discursiva. Bhatia (2009, p.162) chama de aspectos convencionados, institucionalizados e permissíveis (...) da construção dos gêneros, que têm sido o denominador comum das abordagens dos gêneros em detrimento dos aspectos criativos, inovadores e exploráveis.

Trata-se de um tema que possui relevância por ser atual e de evidente importância. Deste modo, a justificativa para este trabalho está centrada na necessidade de, no futuro, tornar mais justa a sociedade, na formação de bons leitores, por meio da liberdade dos seres humanos perante a leitura e a escrita, onde esses se sentirão donos de suas ações, e capacitados para tomarem as decisões corretas. Assim sendo, Dell'isola (2007, p.12) revela:

\footnotetext{
"Como preconizam os Parâmetros Curriculares Nacionais de Língua Portuguesa (PCNLP), é imprescindível o investimento no trabalho com gêneros textuais em sala de aula, pois os alunos devem ser capazes de ler textos de diferentes gêneros “combinando estratégias de seleção, antecipação, inferência e verificação”.
}

Levando em consideração que no encaminhamento do ensino da Língua Portuguesa, um dos eixos principais da disciplina é trabalhar voltado para o alcance da proficiência na produção de textos e sequências textuais para a produção de escritos no gênero escolar dissertativo e/ou argumentativo (Gonçalves, 2020). E, para o rumo desta direção, há estudos focados para essa discursiva, como Antunes (2010; 2017), além do que concernem à teoria dos gêneros do Discurso, e ao contexto de produção textual, as obras de Santos e colaboradores (2015). Os gêneros do discurso, como falam Bezerra e Bakhtin (2016, p.II):

\footnotetext{
"Todos os diversos campos da atividade humana estão ligados ao uso da linguagem (...). O emprego da língua efetua-se em forma de enunciados (orais e escritos) concretos e únicos, proferidos pelos integrantes desse ou daquele campo da atividade humana".
}

E ainda complementa que:

\footnotetext{
"Esses enunciados refletem as condições específicas e as finalidades de cada referido campo não só por seu conteúdo (temático) e pelo estilo da linguagem, ou seja, pela seleção de recursos lexicais, fraseológicos e gramaticais da língua, mas, acima de tudo, por sua construção composicional. (...) cada campo de utilização da língua elabora seus tipos relativamente estáveis de enunciados, os quais denominamos gêneros do discurso (BEZERRA, 20I6, p.II-I2).
} 
Dentro do espectro dos gêneros textuais, antes é importante falar sobre o letramento e suas complexidades, pois deixar esse ponto de lado é ignorar e simplificar as múltiplas formas e diferentes usos dados para esse fenômeno. $\mathrm{Na}$ linguagem estão incluídos os diversos gêneros que são utilizados e praticados pelas diferentes pessoas, nas diversas esferas sociais, através de propósitos, interesses e funções comunicativas (Oliveira, 2010, p.329).

Os letramentos são diversos, como menciona Oliveira (2010, p.329), que "a valorização dos usos tanto da leitura quanto da escrita como práticas sociais por oposição à compreensão do letramento visto como modelo autônomo e homogeneizante, encapsulado unicamente no processo de escolarização que enfatiza o ler e escrever como habilidade, deu lugar à compreensão de um novo conceito, de natureza plural”. Tendo em vista esse novo quadro, os letramentos locais ganharam maior importância na teoria, e nos diferentes tipos e mundos de letramento, sendo explorados e se tornando mais visíveis (BARTON et al., 1999).

A prática do letramento ocorre em igrejas, escolas, ruas, empresas, lojas, órgãos oficiais, em casa, e esses diferentes letramentos atendem aos diferentes propósitos (OLIVEIRA, 2010). As informações presentes em todas as mídias que propagam notícias apresentam diferentes ideias e diferentes conhecimentos, que são absorvidos por seus consumidores de diferentes modos.

Atualmente o mundo é textualizado e vemos leitura e escrita em todas as partes, como outdoors, placas e faixas, propagandas, e essas estruturas são específicas e de grande valor comunicativo, merecendo atenção, pois consumir e produzir os inúmeros textos que se distribuem nos mais diversos estilos e contextos sociais, repassando informações que, muitas vezes, é negada para esferas da população (OLIVEIRA, 20Io). Diante desse fato, o letramento é mediado por textos, e o uso destes implica em ter consciência de que o uso de determinados textos depende do sistema de atividades nos quais os grupos populacionais estão inseridos, e depende também dos papeis que essas pessoas exercem, nos momentos em que precisam fazer uso do letramento e em determinados momentos (OLIVEIRA, 2010).

Os letramentos são diferentes e constantes, além de dêiticos, ideológicos, culturais e críticos (OLIVEIRA, 20Io) e esse conhecimento é importante para direcionar o estudo dos 
gêneros textuais. Um gênero é, portanto um modo próprio de dizer que revela quem fala e de que lugar fala Como eventos históricos, que estão vinculados à vida social e cultural, os gêneros textuais são moldáveis, imprevisíveis, que transformam, surgem, desaparecem e se cruzam conforme as mudanças sociais e comunicativas (OLIVEIRA, 20I0).

Diante dessas definições, é percebido que os gêneros do discurso são meios sociocomunicativos que surgem no interior das situações da vida diária e que possuem configuração temática, composicional e estilística com propriedades definidas, firmadas, e os papéis e lugares ocupados pelos participantes comunicativos são hierárquicos, institucionalizados, e subjacentes às interações sociais (Gonçalves, 2020). Marcushi (2008) focaliza sua pesquisa em referenciais teóricos que perpassam por metodologias didáticopedagógicas que possuem de base para o ensino da produção textual em Língua Portuguesa, o método de estudos dos gêneros do discurso, denominados gêneros textuais.

A realização desta pesquisa baseia-se nas análises documentais, com a finalidade de detectar os prováveis problemas que contribuem no fracasso escolar, sobretudo nas atividades de leitura e escrita. E ainda, privilegiar a aprendizagem num sentido extenso, abordando a importância de se trabalhar adequadamente a diversidade textual de maneira contextualizada, tornando-se um recurso pedagógico disciplinar indispensável à formação moral, intelectual e social do discente.

Diante destas considerações e com perspectiva de uma melhora considerável de uma nova proposta pedagógica para a utilização dos gêneros textuais, este trabalho tem o objetivo geral de reconhecer a imprescindibilidade dos gêneros textuais no ensino aprendizagem a partir de uma pedagogia que desenvolva ações didáticas, para que sanem as deficiências escolares. Tendo por objetivos da utilização dos gêneros textuais como suporte norteador, relacionar de forma eficaz esses gêneros e o ensino, promover atividades de leitura de forma coerente e clara, desenvolver atividades de escrita, organizar trabalhos utilizando as sequências didáticas, como um guia, pois possibilita a escolha do gênero desejado, tratar de forma madura a imprescindibilidade dos gêneros textuais.

Este trabalho segue apresentando um panorama acerca dos gêneros textuais relacionando-os ao ensino da Língua Portuguesa, enfatizando a leitura além da decodificação, a escrita como atividade de recriação; as sequências didáticas como componentes textuais e relevância da imprescindibilidade dos gêneros textuais. Essas questões abordadas servem de suporte para encorajar medidas que venham a facilitar as 
construções de textos, sejam estes falados ou escritos, articulando desta forma, o processo de formação do leitor/escritos, bem como a aquisição de outras habilidades, tanto na escola quanto fora dela.

O presente trabalho visa esclarecer e ressaltar a importância do ensino da Língua Portuguesa por meio do uso de gêneros textuais, onde se constata o fracasso escolar em vários níveis de ensino, com o intuito de propor ideias para uma proposta pedagógica na prática de atividades de leitura, escrita com textos que fazem parte da realidade do cotidiano dos alunos. Além de defender o uso dos gêneros textuais, nos contextos escolares ou extraescolares, atribuindo suas definições, promovendo o desenvolvimento de metodologias e seus usos.

\section{GÊNEROS TEXTUAIS}

No que diz respeito aos gêneros textuais, é compreendida que estes são unidades textuais dados, estáticos, descontextualizados, e com características que são identificáveis facilmente, prontas para serem ensinadas (OLIVEIRA, 20Io). O gênero, no entanto, não se constitui em um fenômeno puro. Johns (2006) atesta que o gênero é afetado por diversas variáveis que operam em conjunto, tornando-o, assim, multifacetado e complexo. Os gêneros textuais são textos de qualquer natureza, sendo eles literários ou não. Segundo Marcushi (2002, p.22-23):

\footnotetext{
"Os tipos textuais abrangem cerca de meia dúzia de categorias conhecidas como: narração, argumentação, exposição, descrição e injunção. Já os gêneros textuais, são inúmeros e são: telefonema, sermão, carta comercial, carta pessoal, bilhete, reportagem jornalística, aula expositiva, reunião de condomínio, notícias jornalísticas, horóscopo, receita culinária, bula de remédio, lista de compras, cardápio de restaurante, instruções de uso, outdoor, inquérito policial, resenha, edital de concurso, piada, conversação espontânea, conferência, carta eletrônica, bate-papo por computador, aulas virtuais e assim por diante."
}

Todo texto organiza-se dentro de um determinado gênero que, por sua vez, constitui formas relativamente estáveis de enunciados disponíveis na cultura, caracterizados por três elementos: conteúdo temático, estilo, e construção composicional. Pode-se ainda afirmar que a noção de gêneros refere-se à família de textos que compartilham algumas características em comum, embora heterogêneas, como visão geral 
da ação à qual o texto se articula, tipo de suporte comunicativo, extensão, grau de liberdade, por exemplo, existindo em números quase ilimitados (BRASIL, 200I).

Desde a infância, o indivíduo é capaz de decifrar a que tipo de gênero o texto é abordado porque houve situações que permitam reconhecer a pertinência de cada gênero textual. Assim sendo, que se vê uma lista de ingredientes e o modo de preparo, sabe-se que é uma receita culinária; quando o texto inicia-se com "senhoras e senhores", trata-se de um discurso público, e assim por diante.

Desde os mais remotos tempos até atualmente, os gêneros literários vêm se renovando. Os seres humanos primitivos não conheciam a escrita, mas ainda assim se comunicavam através de gestos e de desenhos. Atualmente na sociedade moderna, há diversas fontes e formas ainda mais eficazes de comunicação como: e-mail, Facebook, Instagram, o que só vêm a acrescentar a necessidade de comunicação entre os indivíduos.

Em relação à variedade de gêneros e a necessidade de comunicação que acompanha o desenvolvimento da humanidade, Bakhtin (1979, p.3I) escreve:

\footnotetext{
“A riqueza e a variedade dos gêneros são infinitas, pois a variedade virtual da atividade humana é inesgotável e cada esfera dessa atividade comporta um repertório dos gêneros do discurso que vai diferenciando-se e ampliando-se à medida que a própria esfera se desenvolve e fica mais completa."
}

A aprendizagem por meio de gêneros está ligada às formas de comunicação, de expressão de organizar ideias em determinada situação. Desta forma, uma sociedade organizada exerce sua cidadania, haja vista que a comunicação é uma ferramenta essencial e necessária para a construção de seres engajados no fortalecimento de esferas sociais mais homogêneas.

O teórico Shchenewly (2004, p.45) elaborou três critérios para os gêneros serem trabalhados nas escolas, sendo eles:

a) Correspondem a grandes finalidades sociais atribuídas ao ensino, cobrindo dos domínios essenciais de comunicação escrita e oral em nossa sociedade;

b) Retomem de maneira flexível, certas distinções tipológicas, da maneira como já funcionam em vários manuais, planejamentos e currículos;

c) Sejam relativamente homogêneos quanto à capacidade de linguagem implicadas no domínio dos gêneros agrupados. 
A divisão dos gêneros separados de acordo com seus aspectos tipológicos e como devem ser trabalhados no espaço escolar pode ser observada no Quadro I.

Quadro I. Agrupamento de Gêneros Textuais

\begin{tabular}{|c|c|c|c|}
\hline $\begin{array}{l}\text { Deminios sociais } \\
\text { de comuniescjo }\end{array}$ & $\begin{array}{l}\text { Aspectos } \\
\text { tipolbgicos }\end{array}$ & $\begin{array}{l}\text { Capacidacles de } \\
\text { linguagem }\end{array}$ & $\begin{array}{l}\text { Exemplos de gêneros oraìs e } \\
\text { escritos }\end{array}$ \\
\hline $\begin{array}{l}\text { Cultuid bistabie } \\
\text { fiocional }\end{array}$ & Neerar & 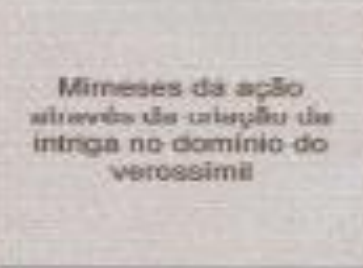 & 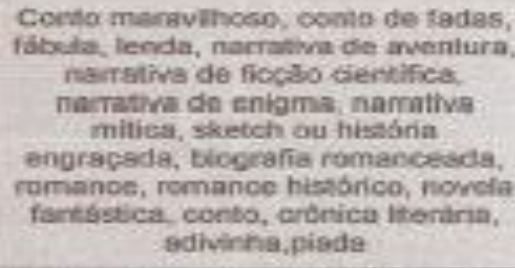 \\
\hline $\begin{array}{l}\text { Documentegso e } \\
\text { mernarizaça das } \\
\text { açōes humanas }\end{array}$ & Relatar & $\begin{array}{l}\text { Representagsa pelo } \\
\text { decurso de } \\
\text { experitincias vimidas, } \\
\text { sibadas no tempo }\end{array}$ & 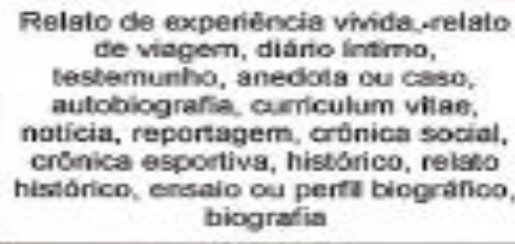 \\
\hline $\begin{array}{l}\text { Descussilo da } \\
\text { problemas sociais } \\
\text { controverses }\end{array}$ & Augurnentar & $\begin{array}{c}\text { Busantegsio, rehutacilo } \\
\text { e negociapto de } \\
\text { tomadas de posiça }\end{array}$ & 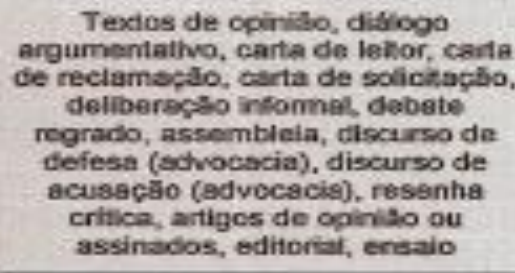 \\
\hline $\begin{array}{c}\text { Transmissio e } \\
\text { construgbo de } \\
\text { saberes }\end{array}$ & Expor & $\begin{array}{c}\text { Apresentaçaso tesctusal de } \\
\text { diferentos fommas dos } \\
\text { saberes }\end{array}$ & 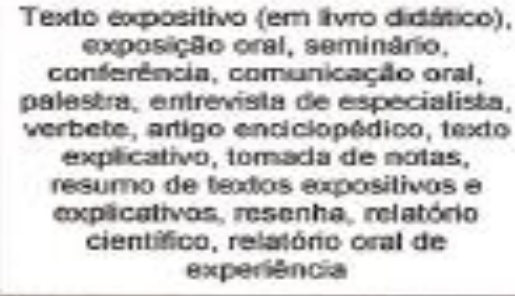 \\
\hline $\begin{array}{l}\text { Anshucoles } 8 \\
\text { pirescrichess }\end{array}$ & $\begin{array}{l}\text { Descrever } \\
\text { açdes }\end{array}$ & $\begin{array}{l}\text { Regulaçro mitua de } \\
\text { compotamentos }\end{array}$ & 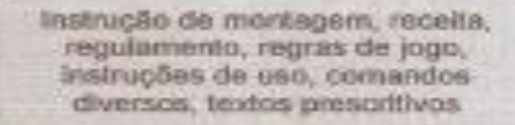 \\
\hline
\end{tabular}

Fonte: Dolz, Shcheneuwly, 2004, p.6o-6r.

\section{OS GÊNEROS TEXTUAIS}

Trabalhar os gêneros textuais em sala de aula é uma excelente oportunidade de se lidar com a Língua nos seus mais diversos usos do cotidiano. Sabe-se que a comunicação é realizada por meio de textos, que não necessariamente precisam ser escritos. É de suma importância possibilitar aos estudantes a oportunidade de produzir e compreender textos de maneira adequada a cada situação de interação comunicativa. O professor pode 
envolver os alunos através de situações concretas de uso da língua, para que consigam, de forma consciente, escolher meios adequados aos fins que se deseja alcançar.

Explorando diversidades textuais, o professor possibilita uma íntima aproximação do aluno com situações originais de produção de textos, proporcionando a compreensão de funcionamento de leitura, de produção textual e de compreensão. Dell'Isola (2007, p.II) escreve:

\footnotetext{
"Consta-se a urgência de se promover a formação de leitores e escritores capazes de compreender e interpretar as relações sociais: de se compreender identidades e formas de conhecimento veiculadas através de textos em variadas circunstâncias de interação: de se levar em conta a determinação sócio-histórica de interação escritor-texto-contexto-leitor, e o de se desenvolver a capacidade de perceber a pluralidade de discursos e possibilidade de organizar do universo."
}

É imensamente interessante trabalhar com recursos viáveis à aprendizagem em termos gerais, o uso de gêneros textuais, como foi visto até o momento, possibilita desafios encorajadores, não só para atividades da Língua, mas também comunga com a ideia de que quanto ser falante e social, o ser humano pode, por meio da língua, modificar o mundo e acreditar que essa mudança é realizada através desta, para a construção de conhecimentos e fortalecimentos à cidadania.

Consoante a Bezerra (2002), a escola tradicional tinha por objetivo nas aulas de língua portuguesa formar alunos reprodutores de modelos abstratos da língua (e não de texto), por isso, é tão importante trabalhar as variedades textuais, como ferramenta norteadora para o ensino da linguagem, fazendo com que os alunos não sejam apenas capazes de tornarem-se leitores e escritores proficientes, mas também compreender suas funções sociais de gêneros, seus usos, sua globalidade, para que possuam veiculá-los, desenvolvendo competências e práticas sociais.

Percebe-se que o trabalho com os gêneros textuais é uma atividade não só ao projeto educacional no indivíduo, mas também no projeto existencial, que além de ser um ato que se realiza no âmbito da cognição, apresenta também caráter social, histórico e político. Os gêneros textuais fazem parte da vida dos seres humanos em todos os momentos, não apenas no âmbito escolar, mas em toda sua rotina. Isso torna a leitura como ato de suma importância na convivência e sociedade. 


\title{
4 LEITURA
}

A leitura significa o exercício da decodificação e codificação mecânica, da repetição (através da interpretação textual, da redação, da memorização), metodologia essa que implica uma consequência: a escola até consegue ensinar o povo a ler, porém não forma leitores. Geraldi (2003, p.70) esclarece:

\begin{abstract}
"Aprender a ler é, assim, ampliar as possibilidades de interlocução com pessoas que jamais encontraremos frente a frente e, por interagirmos com elas, sermos capazes de compreender, criticar e avaliar seus modos de compreender o mundo, as coisas, as gentes, e suas relações. Isso é ler. E escrever é ser capaz de colocar-se na posição daquele que registra suas compreensões para ser lidos por outras e, portanto, com eles interagir."
\end{abstract}

Segundo Freire (1984, p.II) "o ato de ler não se esgota na decodificação pura da escrita, mas se antecipa e se alonga na inteligência do mundo”. Nesse sentido, ler consiste num ato de consciência que não se exaure nele mesmo para resultar numa atividade que busca a compreensão do "ser" e "estar" no mundo. Silva (1987, p.45) afirma que:

\footnotetext{
“Ler é, em última instância, não só uma ponte para a tomada de consciência, mas também um modo de existir no qual o indivíduo compreende e interpreta a expressão registrada pela escrita e passa a compreender-se no mundo."
}

Utilizando palavras de forte carga semântica como conscientização, liberdade, transformação, o autor entende leitura como instrumento para reconstrução da sociedade, apontando ainda a falta de uma política de direito à leitura. Ele completa:

"Na sociedade brasileira, constituída de classes com interesses antagônicos, a leitura se apresenta como uma questão de privilégio e não de direito de toda a população" (SILVA, I986, p.15). Contudo, a leitura e a escrita caminham juntas na construção de saberes e no que diz respeito à comunicação.

\section{ESCRITA}

A escrita é uma atividade complexa que resulta na diversidade de competências, atividades e domínios de decisão que devem estar presentes no aluno. Durante o processo, o educando é chamado a tomar decisões sobre o conteúdo que deverá incluir no seu texto e sobre a linguagem que requer interação, que não é algo mecânico. Para ela ser realizada, é necessário haver uma reflexão acerca do conteúdo a ser abordado. 
A criação de atividades de escrita assume a natureza da recriação, ou seja, de modificações de tarefas, no sentido de adequá-las a determinada situação, ou seja, ao desenvolvimento de competências que, em determinado momento, se quer trabalhar. Nesse contexto, cabe ao professor adequar à sua ação, encontrando especificidades ao tema, destinatários concretos, formas de divulgação, maneiras de realização do processo descrita que se revelem mais proveitosas para o grupo, desta forma, o professor pode tornar as atividades mais significativas para os alunos. O Quadro 2 traz um planejamento de como o professor pode tornar atraente a proposta de produção de texto priorizando o público com quem irá trabalhar. De fundamental importância para a produção de textos, as sequências textuais podem proporcionar a caracterização de um espaço, o relato de um acontecimento, a divulgação de uma opinião e o encaminhamento de uma atividade.

Quadro 2. A escrita como processo de prática social

\begin{tabular}{|c|c|c|c|}
\hline \multicolumn{4}{|c|}{ PRÁTICA SOCIAL DE ESCRITA } \\
\hline \multicolumn{4}{|c|}{ Contexto da produção do texto } \\
\hline \multirow{4}{*}{$\begin{array}{c}\text { Assunto } \\
\text { Motivação } \\
\text { Necessidade } \\
\text { Ideia de leitor }\end{array}$} & \multicolumn{3}{|c|}{ Texio em processo de construção ou já produzido } \\
\hline & \multirow{2}{*}{$\begin{array}{c}\text { Processamento } \\
\text { geraçäo }\end{array}$} & Escrita & Reescrita \\
\hline & & versöes & releituras \\
\hline & \multicolumn{2}{|c|}{ ORGANIZAÇÃO } & REVISÖES \\
\hline \multicolumn{4}{|l|}{ Memória } \\
\hline Assunto & \multicolumn{3}{|c|}{ Monitoração } \\
\hline Língua & \multirow{2}{*}{\multicolumn{3}{|c|}{ Avaliaçäo constante do processo }} \\
\hline Gêneros & & & \\
\hline
\end{tabular}

Fonte: Garcez (2004, p.15)

\section{SEQUENNCIAS TEXTUAIS}

Entende-se por sequências textuais, componentes textuais, constituídos de proposições relativamente estáveis e maleáveis. E que estas estão inseridas no gênero e não 
o oposto. Os gêneros são ilimitados, no entanto, as sequências são delimitadas, como pode ser observado no Quadro 3.

Quadro 3 sequências textuais na teoria de Adam.

\begin{tabular}{|c|c|c|}
\hline Sequência & Relaçōes estabelecidas & Gêneros protótipos \\
\hline Narração & $\begin{array}{l}\text { Processo que organiza os acontecimentos de } \\
\text { maneira a formar um todo com inicio meio e fim, } \\
\text { havendo, portanto, uma sucessão } \\
\text { temporal.Transformação de predicados, relação de } \\
\text { causa/consequência e avaliação final. }\end{array}$ & Fábula, conto, notícia \\
\hline Descrição & $\begin{array}{c}\text { Não há uma ordem linear obrigatória, mas sim a } \\
\text { presença de uma organização espacial delimitada. } \\
\text { Ordem hierárquica, vertical. Processos de } \\
\text { ancoragem, aspectualização, relacionamento. }\end{array}$ & $\begin{array}{c}\text { Anúncio, classificado, } \\
\text { curriculum }\end{array}$ \\
\hline Explicação & $\begin{array}{c}\text { Sintese de conceitos, relações de causa que ligam } \\
\text { os fatos. Constataçăo inicial, problematizaçăo, } \\
\text { resoluçăo, conclusão-avaliação. }\end{array}$ & Texto de divulgação \\
\hline Argumentaçăo & $\begin{array}{l}\text { Presença de uma tese, operações de inferência, } \\
\text { passos argumentativos: premissas, apresentação } \\
\text { de argumentos / contra-argumentos e conclusão. }\end{array}$ & $\begin{array}{l}\text { Editorial, carta } \\
\text { argumentativa, artigo de } \\
\text { opinião }\end{array}$ \\
\hline Dialogal & $\begin{array}{c}\text { Processos de interaçăo verbal, discursos } \\
\text { interativos dialogados, segmentos realizados em } \\
\text { tumos de fala. Intercâmbio de abertura, transicional } \\
\text { e fechamento. }\end{array}$ & $\begin{array}{c}\text { Entrevista, exposição } \\
\text { dialogada }\end{array}$ \\
\hline
\end{tabular}

Fonte: Bonini (2005, p.12)

Diante das informações citadas, verifica-se a importância do trabalho com os gêneros textuais, pois eles são o ponto norteador para sanar dificuldades, adquirir postura madura, exercer sua cidadania. Há, porém, muitos problemas que devem ser citados, e também sanados, pois se isto não ocorrer, os gêneros aqui estudados não passarão de um projeto que nunca deu certo.

\footnotetext{
"O domínio da língua tem estreita relação com a possibilidade de plena participação social, pois é por meio dela que o homem se comunica, tem acesso à informação, expressa e defende pontos de vista, partilha ou constrói visões de mundo, produz conhecimento com a democratização social e cultural, atribui à escola a função e responsabilidade de garantir a todos os seus alunos o acesso aos saberes linguísticos necessários para o exercício da cidadania, direito inalienável de todos." (BRASIL, 200I, p.23).
}

É correto afirmar que para o aluno desenvolver sua competência discursiva, é necessário trabalhar com as variedades textuais, pois a noção do gênero deve ser vista e 
trabalhada como objeto de ensino e não como algo aleatório e mecânico. De acordo com Bezerra (2002, p.213):

\begin{abstract}
"Para evitar que os textos, ao transformarem-se em objeto didático, percam sua força comunicativa e restrinjam-se apenas a seus aspectos estruturais ou formais, é importante que as aulas de Português sejam planejadas para alcançar objetivos mais amplos, que extrapolem a sala de aula, talvez a escola. Assim, é fundamental que os envolvidos no processo de ensino-aprendizagem (professor, alunos, coordenador, diretor, pais) despojem-se da crença de que o essencial é expor os conteúdos programáticos para que o aluno os memorize e repita-os em um teste ou exame (mesmo que não saiba relacioná-los a nenhum aspecto da sua experiência, das suas atividades, a não ser esse teste ou exame)".
\end{abstract}

Bezerra (2002) afirma que a escola ainda age como a escola tradicional, que o mais importante seria a avaliação para se obter uma nota, através de conteúdos, previamente estudados, resumidos, atividades repetidas e programadas para este único objetivo: o de repeti-los numa prova. O mais satisfatório seria a integração de todos os participantes do processor escolar, tendo assim, objetivos extraescolares, ou seja, também fora dos muros da escola.

Outra deficiência no âmbito escolar é apontar para o Livro Didático (LD) como último suporte de apoio nas aulas de língua portuguesa. Souza (1995, p.I17) expõe:

\begin{abstract}
"O professor pode ter uma atitude crítica em relação ao Livro Didático buscando questionar-se a respeito da adequação do material a determinada realidade de ensino ou ele pode, ainda, sentir-se inseguro quanto ao seu preparo profissional, buscando apoio no Livro Didático, utilizando-o enquanto "muleta". Ele passa, assim, a seguir o manual do professor como referência essencial para suas aulas e dele extraindo, por vezes na íntegra, textos, exercícios, etc., por sentir-se despreparado para realizar um trabalho de avaliação ou adaptação do material didático".
\end{abstract}

A autora aponta que para muitos professores o LD é o único recurso utilizado por eles nas aulas, revelando muitas vezes o seu despreparo, uma formação inadequada, uma postura inconsciente, pois não deve esperar do livro didático todo um desempenho que o aluno deva alcançar. Os gêneros estão em todos os lugares, nos livros, jornais, revistas, cartas, placas de trânsito, numa frase, etc. destes recursos o educador pode extrair e deixar que o aluno extrair seus sentidos, suas inferências. Que seja permissível acrescentar, modificar, reestruturar, fazer uma atividade que instigue a capacidade de criar e estruturar relações tanto para a ação escolar quanto fora dela. 
O ensino de leitura/produção textual com base nos gêneros textuais, segundo Koch e Elias (20ı), poderá favorecer importantes contribuições para a mudança de forma de tratamento da produção textual na escola. Contribuições estas que podem trazer no ensino de línguas, tanto língua materna quanto de língua estrangeira, que vai além do aprendizado do código.

\section{CONIDERAÇÕES FINAIS}

A presente pesquisa teve por objetivo reconhecer a imprescindibilidade do uso dos gêneros textuais como instrumento norteador na esfera pedagógica, revelando as suas multipráticas, que permitem o ingresso ao mundo das interações, da descoberta, do despertar para uma vida repleta de buscas pelo conhecimento. As questões que foram abordadas servem de suporte, para encorajar medidas que venham a facilitar as construções de textos, sejam estes falados ou escritos. Articulando desta forma no processo de formação de leitor/escritor. Bem como na aquisição de outras habilidades tanto na escola, quanto fora dela.

Os gêneros textuais são uma conexão do modo em que se vive, para um mundo desconhecido, existindo em toda e qualquer sociedade utiliza-se um ou mais tipos de gênero inerente à realidade dos falantes, mostrando sua dimensão. Enfim, este trabalho promoveu uma reflexão sobre o investimento do assunto abordado: os gêneros textuais, pois eles permitem a seus falantes: interpretar as relações sociais, desenvolver a capacidade de realizar discursos, realizar atividades voltadas ao estudo da língua, partilha visões de mundo, infere o que há nas entrelinhas dos textos, expressa seu ponto de vista, reavalia suas ações quanto ser falante e social, interagindo com outros indivíduos. Este investimento, porém, requer cuidados, pois não há modelo "pronto" a ser seguido. As metodologias devem ser bem elaboradas, aprofundadas e planejadas em primeiro plano, que podem resultar no amadurecimento de habilidades e competências, reencontro consigo mesmo e exercendo, então, a cidadania.

\section{REFERÊNCIAS}

ANTUNES, Irandé. Análise de textos: fundamentos e práticas. São Paulo, Parábola. 2010. 224p. 
ANTUNES, Irandé. Textualidade: noções básicas e implicações pedagógicas. ı.ed. São Paulo: Parábola, 2017. 168p.

BAKHTIN, Michael Ladislav; POMOVSKA'S, Krystyna. Reading in Russian Poetics. 1979. 306p.

BARTON, David; HAMILTON, Mary; IVANIČ, Roz. Situated Literacies. London: Routledge, 1999. 240p.

BHATIA, Vijay K. A análise de gêneros hoje. In: BEZERRA, Benedito Gomes et al. Gêneros e Sequências Textuais. Recife: Edupe, 2009. 159-196.

BEZERRA, Maria Auxiliadora (Org.). Gêneros textuais e ensino. 2.ed. Rio de Janeiro: Lucerna, 2002. 248p.

BEZERRA, Paulo; BAKHTIN, Mikhail. Os gêneros do discurso. r.ed. São Paulo: 34 Editora, 2016. 176p.

BONINI, Adair; MOTTA-ROTH, Désirée (Orgs.). Gêneros, teorias, métodos, debates. São Paulo: Parábola, 2005. 295p.

BRASIL, Ministério da Educação e do Desporto. Secretaria da Educação Fundamental. Parâmetros Curriculares Nacionais. 3.ed. Brasília: MEC/SEF, 20oI.

DELL'ISOLA, Regina Lúcia Péret. Retextualização de gêneros escritos. Rio de Janeiro: Lucerna, 2007. 96p.

FREIRE, Paulo. A importância do ato de ler em três artigos que completam. 7.ed. Campinas, São Paulo: Cortez, 1984. 104p. 
GARCEZ, Lucília Helena do Carmo. Técnica de redação - o que é preciso saber para bem escrever. São Paulo: Martins Fontes, 2004. 154p.

GERALDI, João Wanderley. Postos de passagem. 4.ed. São Paulo: Martins Fontes, 2003. $28 \mathrm{p}$.

GONÇALVES, Tatiana da Conceição. Gêneros discursivos/textuais, sequências textuais, planos de texto e ensino de Língua Portuguesa: perspectivas para o desenvolvimento de um projeto de escrita proficiente. In: Argumentação e Linguagem 3. PURIFICAÇÃO, Marcelo Máximo. SOARES, Katielly Vila Verde Araújo. FERREIRA, Denilra Mendes. Atena Editora, 2020. 167-175.

JHONS, Ann M. et al. Crossing the boundaries of genre studies: commentaries by experts. Journal of Second Language Writing, I. 2006. 234-249.

KOCH, Ingedore Villaça; ELIAS, Vanda Maria. Ler e compreender: os sentidos do texto. 3.ed. são Paulo: Contexto, 2010. 216p.

MARCUSHI, Luiz Antônio. Gêneros textuais: definição e funcionalidade. In: DIONISIO, A.P. et al. (org.). Gêneros textuais \& Ensino. Rio de Janeiro: Lucerna, 22-23. 2002.

MARCUSHI, Luiz Antônio. Produção textual, análise de gêneros e compreensão. São Paulo: Parábola, 2008. 296p.

OLIVEIRA, Maria do Socorro. Gêneros textuais e letramento. Revista Brasileira de Linguística Aplicada, io. 2010. 325-345.

SANTOS, Leonor Werneck; RICHIE, Rosa Cuba; TEIXEIRA, Cláudia Souza. Análise de produção de textos. São Paulo: Contexto, 2015. 192p. 
SHCHENEWLY, Bernard. Gêneros orais e escritos na escola. São Paulo: Mercado de Letras, 2004. 240p.

SILVA, Ezequiel Theodoro. Leitura na escola e na biblioteca. Campinas: Papirus, 1986. 82p.

SILVA, Ezequiel Theodoro. $O$ ato de ler: fundamentos psicológicos para uma nova pedagogia da leitura. 4.ed. são Paulo: Cortez, 1987. ı2op.

SOUZA, Deuza Maria. Do monumento ao documento. In: CORACINI, Maria José Rodrigues Faria (org.). O jogo do discurso na aula de leitura: língua maternal e língua estrangeira. Campinas: Pontes, 1995. I4Ip. 